\title{
An appraisal of infants with murmurs referred to a cardiac clinic
}

\author{
Rajeev Sathanantharajah ${ }^{1}$, S Sivakumar $^{2}$, V Gali $^{3}$ \\ Sri Lanka Journal of Child Health, 2011; 40(3): 125-127
}

DOI: http://dx.doi.org/10.4038/sljch.v40i3.3510

\begin{abstract}
Objective: Appraisal of infants with murmurs referred to a cardiac clinic.

Method: Retrospective analysis of all infants with newly heard murmurs referred from April 2007 to October 2009 to cardiac clinics run by a paediatrician with special expertise in cardiology in the City Hospital and Sandwell General Hospital in the West Midland, UK.
\end{abstract}

Results: During the study period, 246 infants were referred for murmurs. Of the referrals $55 \%$ were following postnatal checks and $45 \%$ from paediatric clinics and general practitioners. All infants had clinical examinations, saturation checks and electrocardiograms. Echocardiograms were done when needed. In 88 (36\%) infants no murmurs were heard during assessment and no follow-up was needed. In 158 (64\%) infants murmurs were heard during assessment. Fifty four (34\%) infants with innocent murmurs and normal echocardiograms were discharged from the clinic. All $13(8 \%)$ infants with patent foramen ovale (PFO) showed closure of PFO on subsequent follow up. Cardiac defects (excluding PFO) were found on echocardiogram in $91(58 \%)$ infants. Of the 91 infants $24(26 \%)$ with significant cardiac defects were referred to the nearest tertiary cardiac centre for further management.

Conclusions: The prevalence of murmurs detected at routine neonatal examination was $0.7 \%$. Fifty eight percent of infants with murmurs had cardiac defects $26 \%$ of which were significant.

(Key words: Cardiac murmurs; infants; appraisal)

\section{Introduction}

Up to four in every 1000 live born babies have a

${ }^{1}$ Neonatal Paediatrician, Neonatal Unit, Teaching
Hospital (Mahamodara) Galle, Sri Lanka,
${ }^{2}$ Neonatal Paediatrician, Neonatal Unit, City
Hospital, Birmingham, UK, ${ }^{3}$ Paediatric Trainee
(ST5), Birmingham Children's Hospital,
Birmingham, UK

(Received on 21 October 2010: Accepted on 17 December 2010) cardiovascular malformation which presents in infancy $^{1,2}$ but most are asymptomatic at birth. Auscultation of the heart during routine neonatal examination before discharge from hospital provides an opportunity for early diagnosis. Murmur is the most common presentation of congenital heart disease. There are instances where the murmurs are detected in the post neonatal period. Reviewing these two groups in the paediatric cardiology clinic provides an opportunity for assessment.

\section{Objective}

Appraisal of infants with murmurs referred to a cardiac clinic.

\section{Method}

A cardiac clinic was run by a paediatrician with special interest in cardiology in the City Hospital and Sandwell General Hospital in the West Midland, UK. Infants presenting with cardiac murmur during the first year of life in these two hospital areas were referred to this cardiac clinic. Data was obtained from the clinic notes and referral letters over a 30 month period from April 2007 to October 2009. Fifty five percent of the referrals came from routine neonatal checks and $45 \%$ from paediatric clinics and general practitioners.

Routine neonatal examination in the City Hospital and Sandwell General Hospital was undertaken by senior house officer, neonatal paediatricians and advanced neonatal nurse practitioners within 72 hours of delivery. All had received identical training in neonatal examination. Infants who were ill and required neonatal intensive care were excluded from the analysis as their examination was not routine.

All infants with murmurs at the time of referral were examined by a middle grade doctor or a consultant. Babies were brought back to the cardiac clinic within two to 42 days depending on the saturations and ECG findings. The echocardiogram permitted early accurate anatomical diagnosis either to reassure parents that the heart was normal, or where heart disease was detected, to explain the nature of the abnormality and, where necessary, to arrange referral for definitive treatment to the 
cardiac centre. Echocardiographic assessment was made by the paediatrician if murmur persisted.

\section{Results}

During the study period, 18,923 neonates underwent routine examination in the City Hospital and Sandwell General Hospital and $136(0.7 \%)$ were found to have a murmur and referred to the cardiac clinic. In addition, 110 infants were referred from other paediatric clinics and general practitioners making a total of 246 . Thirty babies, admitted to the neonatal intensive care unit with severe respiratory distress and cyanosis and diagnosed to have cyanotic heart disease were excluded from the study.
All the murmurs were re-examined in the clinic. Murmur could not be heard in $88(36 \%)$ infants and parents were reassured and the infants discharged from the clinic. Of the $158(64 \%)$ infants who had a persistent murmur, $54(34 \%)$ had normal echocardiogram findings and were discharged too. All 158 babies were asymptomatic in the clinic. Abnormalities, excluding patent foramen ovale (PFO), were found on echocardiogram in 91 (58\%). Figure 1 is a flow chart showing progress of all infants included in the study. Figure 2 shows the cardiac defects found on echocardiography and the referrals to cardiac centre.

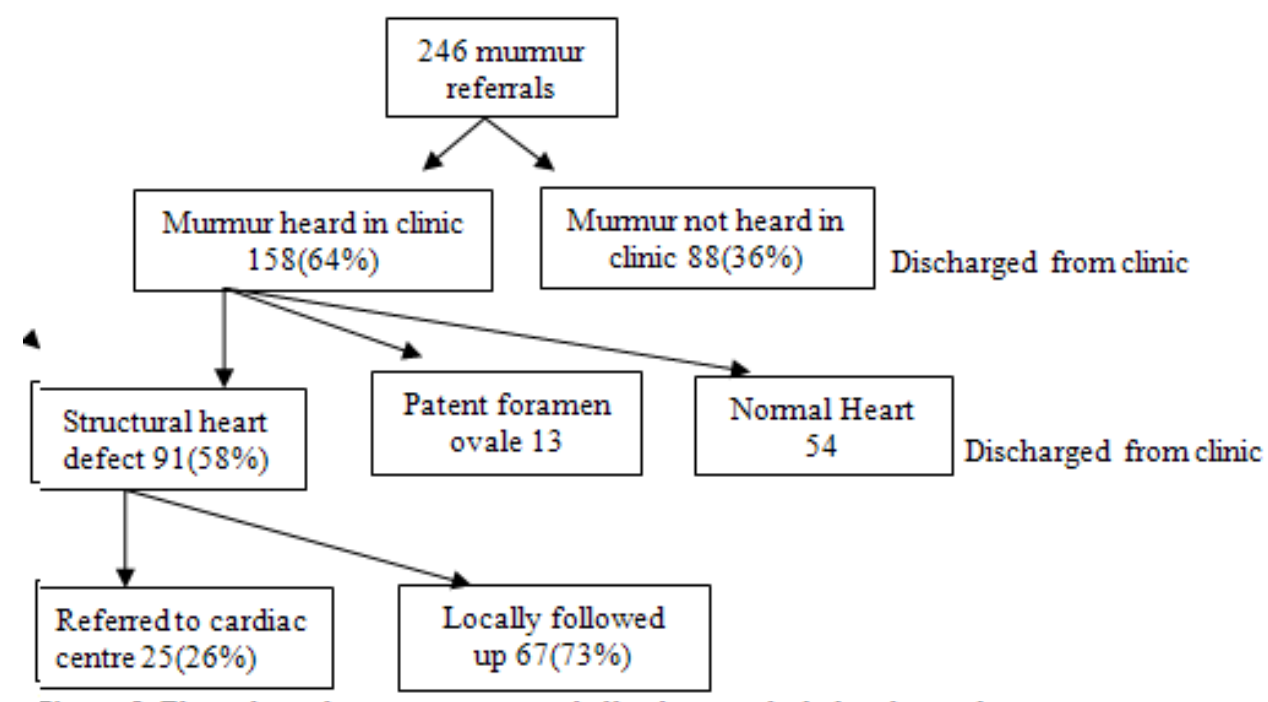

Figure 1 Flow chart showing progress of all infants included in the study

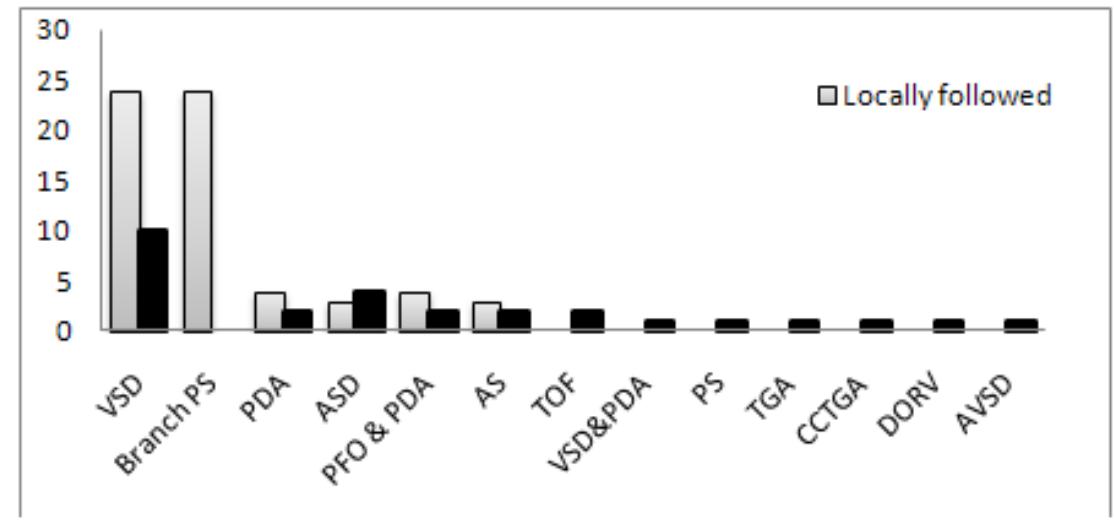

Figure 2 Anatomical diagnosis and referrals

\section{Discussion}

Murmurs were detected in $0.7 \%$ of babies undergoing routine neonatal examination. This is consistent with the prevalence of murmurs in the neonatal period in other studies ${ }^{3}$. In our study $58 \%$ of infants with murmurs had a structural cardiovascular malformation. This is much less than in a study done in Israel where structural lesions were found in $86 \%$, . Twenty six percent of 
infants with murmurs required early tertiary cardiac referral before they became symptomatic. This figure is much higher than in other studies ${ }^{6}$. The most common cardiac defect in our study was VSD and this is very similar to other studies ${ }^{4}$.

Since murmurs may provide a clue to the presence of asymptomatic heart disease, it seems appropriate to refer all such infants for early definitive diagnosis. Beebe et al found that $57 \%$ of neonates dying from cardiovascular malformations after discharge from hospital had had a murmur before discharge ${ }^{7}$.

\section{Conclusions}

- The prevalence of murmurs detected at routine neonatal examination was $0.7 \%$.

- Fifty eight percent of infants with murmurs referred to a cardiac clinic had underlying cardiovascular malformations with VSD being the commonest.

- Twenty six percent of cardiac lesions needed referral to tertiary cardiac centre.

\section{References}

1. Ferencz C, Rubin JD, McCarter RJ, et al. Congenital heart disease: prevalence at live birth. Am J Epidemiol 1985; 121:31-6.

2. Kidd SA, Lancaster PAL, McCredie RM. The incidence of congenital heart defects in the first year of life. J Paediatr Child Health 1993; 29:344-9.

http://dx.doi.org/10.1111/j.14401754.1993.tb00531.x

3. Ainsworth S, Wyllie JP, Wren C. Prevalence and clinical significance of cardiac murmurs in neonates. Arch Dis Child Fetal Neonatal Ed 1999; 80(1):F43-5.

http://dx.doi.org/10.1136/fn.80.1.F43

4. Rein AJ, Omokhodion SI, Nir A. Significance of a cardiac murmur as the sole clinical sign in the newborn. Clin Pediatr (Phila) 2000; 39(9):511-20.

5. Roguin N, Barak M, Du ZD. Clinical and echocardiographic evaluation of neonates with heart murmurs. Acta Paediatr 1997; 86(7):752-6.

http://dx.doi.org/10.1111/j.16512227.1997.tb08580.x

6. Patton C, Hey E. How effectively can clinical examination pick up congenital heart disease at birth? Arch Dis Child Fetal Neonatal Ed 2006; 91(4):F263-7.

7. Beebe SA, Britton JR, Britton HL, Fan P, Jepson B. Neonatal mortality and length of newborn hospital stay. Pediatrics 1996: 98:231-5. 